\author{
Maria Pia Prudenzano \\ Mario Guazzelli \\ Anna Pia Verri \\ Salvatore Misceo \\ Vittorio Sciruicchio \\ Giuseppe Libro • Maria Nicolodi \\ Stefania Canova \\ Franca Moschiano \\ Licia Grazzi • Domenico D'Amico \\ Ferdinando Maggioni \\ Giuliano Relja \\ Giorgio Sandrini • Andrea Alberti \\ Susanna Russo
}

\section{Quality of life and illness behaviour in chronic daily headache patients}

M.P. Prudenzano $(\varangle) \cdot$ S. Misceo

V. Sciruicchio $\bullet$ G. Libro

Neurological Clinic I,

University of Bari, Policlinico,

Piazza Giulio Cesare 11, I-70124, Bari, Italy

e-mail: m.p.prudenzano@neurol.uniba.it

Tel.: +39-080-5592331

Fax: +39-080-5478532

The affiliations of the other authors are listed at the end of the article

\begin{abstract}
Chronic pathologies, above all those in which is present pain, can induce a considerable impairment in quality of life. The concept of illness behaviour is closely related to that of quality of life. It can be defined as the way to estimate and to react to one's own health status. In this study on chronic headache patients, the sickness impact profile (SIP) was used as a measure of illness-related quality of life. The way of experiencing the disease was moreover quantified by means of the illness behaviour questionnaire (IBQ). Patients with chronic
\end{abstract}

headache showed a remarkable impairment in most of their daily activities. At the same time, they lived their illnesses poorly. The longer was chronic headache duration, the more disability was marked. Female gender was associated with a more severe profile, both in SIP and in $I B Q$.

Key words Quality of life • SIP.IBQ Disability $\cdot$ Illness $\cdot$ Behaviour .

Chronic daily headache $\cdot$ Drug abuse

\section{Introduction}

Quality of life can be considered to be a condition of complete physical, psychological and social wellbeing, and not only the absence of disease. Numerous factors, some of which relate to the individual (e.g. psycho-affective profile, personality), some others to the environment (e.g. type of relationship and degree of familiar and social involvement), enter in game in determining the quality of one's life.

Chronic pathologies, above all those in which pain is present, become part in this complex equilibrium, inducing a fall of the quality of life. Consequently it can be assumed that chronic headache results in considerable impairment in quality of life.

The concept of illness behaviour is closely related to that of quality of life. It can be defined as the way to estimate and to react to one's own health being.

The appraisal of the disability, considered as a restriction or lack of the ability to carry out activities and to manage roles in the ways considered normal, offers an estimate of the impact of headache on the life of the patient.
In recent years, numerous studies have addressed the ideation of effective instruments for the measurement of the quality of life, some of non-specific type and some others specific for certain pathologies. In this study of chronic headache patients, Sickness Impact Profile (SIP) [1], a non-specific test that assesses even the smallest alterations of functioning reportable to one determined pathology, was used to measure illness-related quality of life. The way of experiencing disease was moreover quantified by means of the Illness Behaviour Questionnaire (IBQ) [2].

\section{Patients and methods}

A total of 157 patients, including 120 women and 37 men between 18 and 65 years of age, suffering from a primary headache for at least 15 days per month for at least 6 months and referred to nine Italian headache centres, were consecutively recruited and admitted to the study. Exclusion criteria were: diagnosis of chronic cluster headache, chronic paroxysmal hemicrania, hemicrania continua, chronic posttraumatic headache and schizophrenia or cognitive deficit which could impair the co-operation of the patient. The demographic char- 
acteristics of the sample are summarised in Table 1. The clinical evaluation was based upon the following parameters: a clinical-descriptive analysis of chronic daily headache; a card on analgesics overuse. Quality of life changes related to headache were evaluated by means of the SIP which investigates 12 areas of daily life activity: sleep and rest (SR), emotional behaviour (EB), body care and movement $(\mathrm{BCM})$, home management (HM), mobility $(\mathrm{M})$, social interaction $(\mathrm{SI})$, ambulation $(\mathrm{A})$, alertness behaviour $(\mathrm{AB})$, communication $(\mathrm{C})$, work (W), recreational pastime (RP), and eating (E). This test also supplies three general indices: physical (SDI), psychosocial (SDII) and overall distress (SIP).

The way of living headache was assessed with the IBQ that investigates: general hypochondriasis $(\mathrm{GH})$, disease conviction (DC), psychological vs. somatic perception of illness ( $\mathrm{PvS})$, affective inhibition (AI), affective disturbance (AD), denial (D), irritability (I), and index of hypochondriasis (IH).

In both SIP and IBQ, higher scores indicate a higher impairment (the normal value is 0 ).

Pearson's test was applied to calculate possible correlations between each SIP and IBQ parameter and headache clinical charactersitics (age, age at headache onset, age at chronic headache onset, chronic headache duration and total headache duuration). Student's $t$ test for independent data was used to compare means from two samples (men vs. women, abusers vs. nonabusers), and the one-way ANOVA was used to compare means from more than two samples (chronic headache subtypes).

\section{Results}

At the time of observation, the headache fulfilled the diagnostic criteria for migraine in 48 patients $(30.6 \%)$, for chronic tension-type headache in 39 patients $(24.8 \%)$ and for a combination of the two previous types in 70 patients (44.6\%). The type of headache at the beginning of clinical history was: migraine without aura in 104 patients $(66.2 \%)$, migraine with aura in 10 patients $(6.4 \%)$, episodic tension-type headache in 19 patients $(12.1 \%)$, a combination of migraine and tensiontype headache in 2 patients $(1.3 \%)$, and de novo chronic daily headache in 17 patients $(10.8 \%)$; 4 (2.6\%) patients could not be classified according IHS criteria, and one case $(0.6 \%)$ was not diagnosed. Of the 157 patients, 102 (64.9\%) fulfilled the IHS diagnostic criteria for analgesics abuse headache. The mean SIP profile of the chronic daily headache sample showed that the disability degree was higher than $15 \%$ in six dimensions and in two general indices (Fig. 1). Figure 2 shows the

Table 1 Demographic characteristics of the patient sample. Values are means (standard deviation)

\begin{tabular}{|c|c|c|c|c|c|c|}
\hline \multirow[b]{2}{*}{ Age, years } & \multicolumn{2}{|c|}{$\begin{array}{c}\text { Men } \\
(\mathrm{n}=37)\end{array}$} & \multicolumn{2}{|c|}{$\begin{array}{l}\text { Women } \\
(\mathrm{n}=120)\end{array}$} & \multicolumn{2}{|c|}{$\begin{array}{c}\text { Total } \\
(\mathrm{n}=157)\end{array}$} \\
\hline & 38.7 & $(12.7)$ & 44.1 & (12.9) & 42.8 & $(13.0)$ \\
\hline Education, years & 12.4 & (3.7) & 10.1 & (3.7) & 10.7 & $(3.8)$ \\
\hline Age at headache onset, years & 19.4 & $(8.1)$ & 20.5 & $(10.5)$ & 20.2 & $(10.0)$ \\
\hline Age at chronic headache onset, years & 34.1 & (13.4) & 37.4 & (12.3) & 36.7 & $(12.6)$ \\
\hline Headache duration, years & 19.3 & $(14.0)$ & 23.6 & $(13.4)$ & 22.6 & $(13.6)$ \\
\hline Chronic headache duration, years & 4.6 & $(5.6)$ & 6.6 & $(6.8)$ & 6.1 & $(6.6)$ \\
\hline
\end{tabular}

Fig. 1 Mean SIP profile in chronic headache patients

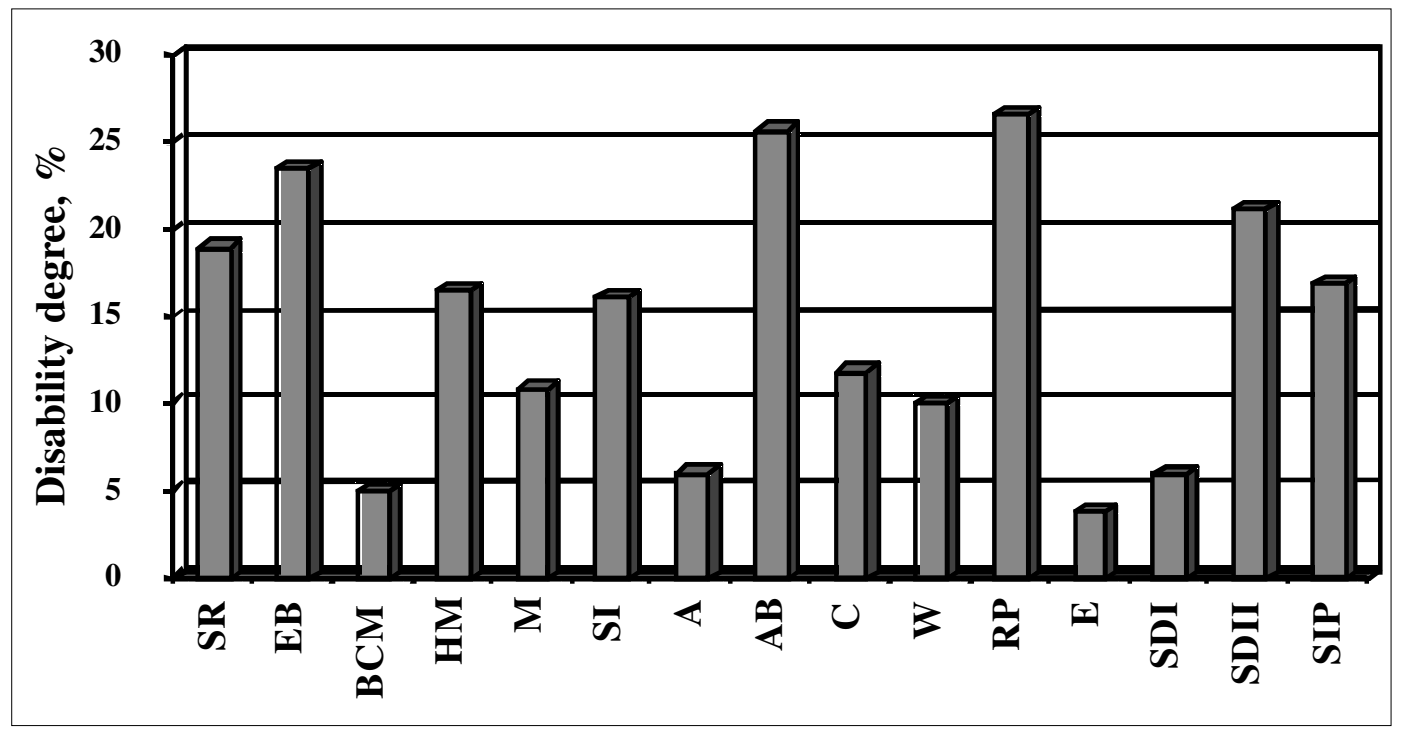


Fig. 2 Mean IBQ profile in chronic headache patients

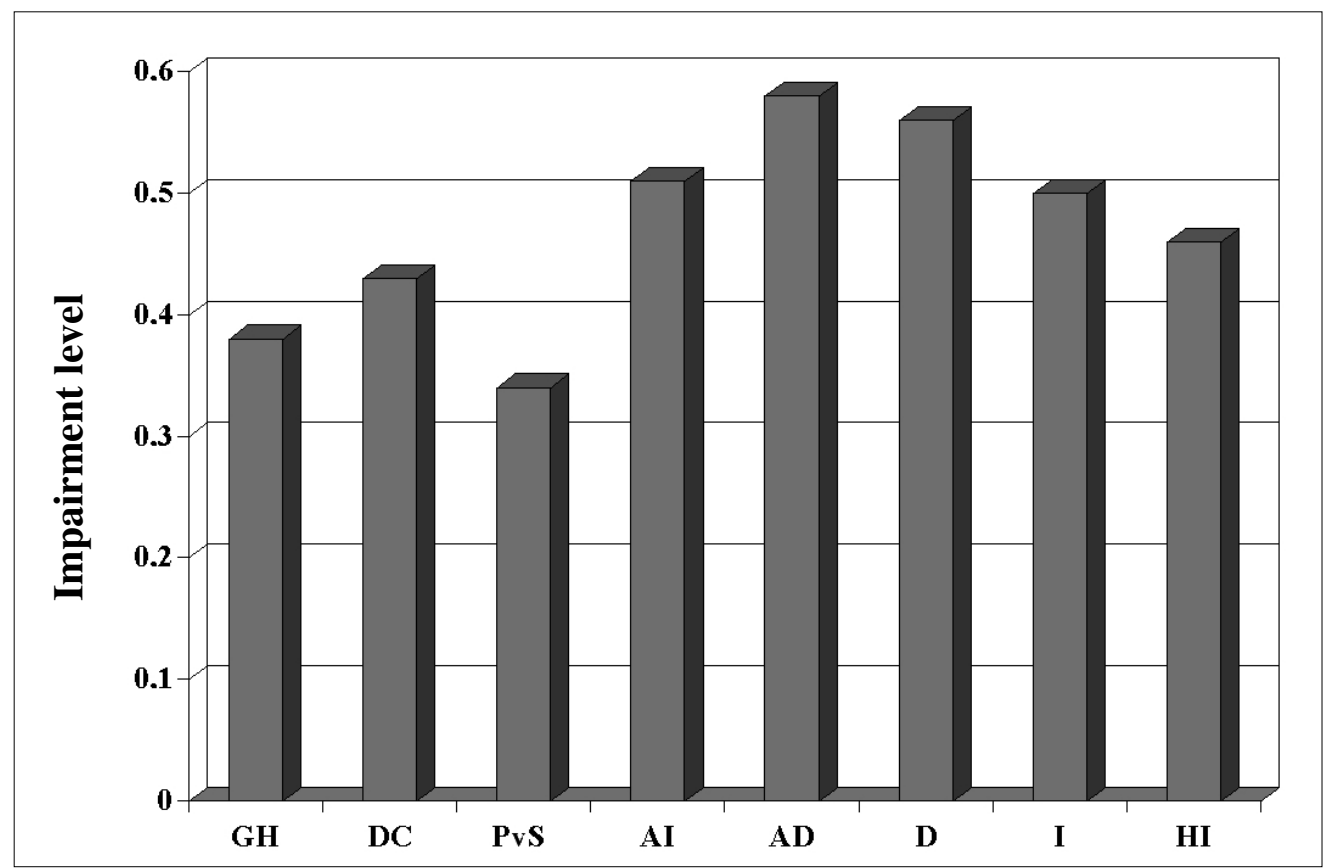

headache patients' mean IBQ profile which is characterized by an impairment level higher than 0.30 in all dimensions.

A positive correlation was found between a great number of SIP parameters (SR, EB, HM, M, A, C, SDI, SIP) and patient's age (Table 2). The same parameters showed a positive correlation with age at headache onset. The work functioning impairment was positively correlated to chronic headache duration. An adjunctive correlation was demonstrated between HM and headache total duration, and finally between A and headache total duration (Table 2).

The results of Pearson's test applied to IBQ parameters showed a positive correlation of numerous test parameters (GH, DC, PvS, D and HI) either with age at headache onset or with age at chronic headache onset (Table 3). A positive cor-

Table 2 Bivariate correlation between the sickness impact profile parameters and some clinical parameters in 157 patients with chronic headache

\begin{tabular}{|c|c|c|c|c|c|c|c|c|c|c|}
\hline & \multicolumn{2}{|c|}{ Age } & \multicolumn{2}{|c|}{$\begin{array}{c}\text { Age at } \\
\text { headache onset }\end{array}$} & \multicolumn{2}{|c|}{$\begin{array}{l}\text { Age at chronic } \\
\text { headache onset }\end{array}$} & \multicolumn{2}{|c|}{$\begin{array}{c}\text { Chronic headache } \\
\text { duration }\end{array}$} & \multicolumn{2}{|c|}{$\begin{array}{l}\text { Headache } \\
\text { duration }\end{array}$} \\
\hline & $\mathrm{r}$ & $p$ & $\mathrm{r}$ & $p$ & $\mathrm{r}$ & $p$ & $r$ & $p$ & $r$ & $p$ \\
\hline SR & 0.19 & 0.018 & 0.21 & 0.008 & 0.17 & 0.02 & 0.03 & 0.7 & 0.02 & 0.74 \\
\hline EB & 0.18 & 0.02 & 0.15 & 0.053 & 0.14 & 0.07 & 0.08 & 0.31 & 0.05 & 0.47 \\
\hline BCM & 0.06 & 0.40 & -0.001 & 0.99 & 0.07 & 0.39 & 0.02 & 0.97 & 0.06 & 0.41 \\
\hline HM & 0.24 & 0.002 & 0.10 & 0.20 & 0.26 & 0.001 & -0.01 & 0.84 & 0.16 & 0.04 \\
\hline M & 0.15 & 0.05 & 0.05 & 0.50 & 0.18 & 0.02 & -0.04 & 0.57 & 0.10 & 0.19 \\
\hline SI & 0.13 & 0.10 & 0.07 & 0.33 & 0.10 & 0.19 & 0.05 & 0.47 & 0.06 & 0.39 \\
\hline A & 0.20 & 0.01 & 0.03 & 0.66 & 0.18 & 0.02 & 0.06 & 0.41 & 0.17 & 0.03 \\
\hline $\mathrm{AB}$ & 0.02 & 0.9 & -0.01 & 0.83 & 0.01 & 0.84 & 0.08 & 0.92 & 0.03 & 0.70 \\
\hline $\mathrm{C}$ & 0.15 & 0.06 & 0.12 & 0.11 & 0.17 & 0.02 & -0.04 & 0.60 & 0.05 & 0.53 \\
\hline $\mathrm{W}$ & -0.01 & 0.46 & -0.005 & 0.94 & 0.05 & 0.46 & -0.22 & 0.005 & -0.05 & 0.53 \\
\hline $\mathrm{RP}$ & 0.05 & 0.56 & 0.04 & 0.63 & 0.08 & 0.3 & -0.06 & 0.39 & 0.01 & 0.83 \\
\hline $\mathrm{E}$ & 0.02 & 0.73 & 0.10 & 0.17 & 0.09 & 0.27 & -0.11 & 0.15 & -0.05 & 0.50 \\
\hline SDI & 0.18 & 0.03 & -0.05 & 0.53 & 0.18 & 0.02 & 0.01 & 0.90 & 0.13 & 0.08 \\
\hline SDII & 0.16 & 0.04 & 0.09 & 0.22 & 0.24 & 0.07 & 0.03 & 0.65 & 0.08 & 0.31 \\
\hline SIP & 0.20 & 0.01 & 0.07 & 0.38 & 0.21 & 0.006 & -0.20 & 0.80 & 0.13 & 0.08 \\
\hline
\end{tabular}


Table 3 Bivariate correlation between the illness behaviour questionnaire parameters and some clinical parameters in 157 patients with chronic headache

\begin{tabular}{|c|c|c|c|c|c|c|c|c|c|c|}
\hline & \multicolumn{2}{|c|}{ Age } & \multicolumn{2}{|c|}{$\begin{array}{c}\text { Age at } \\
\text { headache onset }\end{array}$} & \multicolumn{2}{|c|}{$\begin{array}{l}\text { Age at chronic } \\
\text { headache onset }\end{array}$} & \multicolumn{2}{|c|}{$\begin{array}{c}\text { Chronic headache } \\
\text { duration }\end{array}$} & \multicolumn{2}{|c|}{ Headache duration } \\
\hline & $\mathrm{r}$ & $p$ & $\mathrm{r}$ & $p$ & $\mathrm{r}$ & $p$ & $\mathrm{r}$ & $p$ & $\mathrm{r}$ & $p$ \\
\hline $\mathrm{GH}$ & 0.16 & 0.049 & 0.21 & 0.009 & 0.24 & 0.004 & -0.12 & 0.11 & -0.001 & 0.98 \\
\hline DC & 0.26 & 0.001 & 0.08 & 0.29 & 0.24 & 0.002 & 0.04 & 0.58 & 0.18 & 0.02 \\
\hline $\mathrm{PvS}$ & -0.25 & 0.002 & 0.034 & 0.67 & -0.18 & 0.02 & -0.12 & 0.11 & -0.25 & 0.001 \\
\hline AI & 0.08 & 0.29 & 0.05 & 0.47 & 0.05 & 0.49 & 0.06 & 0.44 & 0.03 & 0.64 \\
\hline $\mathrm{AD}$ & 0.15 & 0.06 & 0.029 & 0.71 & 0.13 & 0.08 & 0.03 & 0.67 & 0.12 & 0.13 \\
\hline $\mathrm{D}$ & 0.19 & 0.015 & 0.733 & 0.36 & 0.27 & 0.001 & -0.13 & 0.08 & 0.13 & 0.10 \\
\hline I & -0.04 & 0.64 & 0.002 & 0.98 & -0.04 & 0.59 & 0.01 & 0.90 & -0.03 & 0.64 \\
\hline HI & 0.19 & 0.016 & 0.25 & 0.001 & 0.26 & 0.001 & -0.11 & 0.16 & -0.03 & 0.97 \\
\hline
\end{tabular}

relation was also present between $\mathrm{GH}$ and age at headache onset, DC and total headache duration, PvS and total headache duration, and $\mathrm{HI}$ and age at headache onset (Table 3).

When comparing the SIP mean profiles of women with those of men, a more compromised level was found in most parameters in the former group than in the latter (Table 4). The comparison between drug abusers and nonabusers showed that $\mathrm{C}$ score was significantly higher in abusers, but no other difference was found (Table 4). No difference was found among the three subtypes of chronic headache except for SI (Table 4). In detail, a significant difference $(p<0.05)$ was found in SI scores between chronic migraine (21.58 \pm 22.58) and chronic coexisting migraine and tension-type headache $(12.40 \pm 14.87)$

Women appeared to have a more impaired IBQ profile than men in GH, DC, AD and HI (Table 5). Abusers had higher scores than nonabusers in PvS, I and HI (Table 5). No difference emerged among the three subtypes of chronic headache except for I (Table 5). In fact, in this parameter chronic migraine score $(0.57 \pm 0.24)$ was significantly higher $(p<0.05)$ than that of chronic coexisting migraine and tension-type headache $(0.45 \pm 0.24)$.

Table 4 SIP parameter mean values: comparison according to gender, drug abuse and chronic headache subtype

\begin{tabular}{|c|c|c|c|c|c|c|c|c|c|c|c|c|c|c|}
\hline & & & Ger & $\operatorname{der}^{\mathrm{a}}$ & & & Drų & abuse ${ }^{a}$ & & & $\mathrm{Ch}$ & ic headac & e subty & \\
\hline & Wor & $\operatorname{nen}^{\mathrm{c}}$ & & $n^{c}$ & $p$ & & users $^{\mathrm{c}}$ & Non & abusers ${ }^{\mathrm{c}}$ & $p$ & & & & \\
\hline SR & 21.6 & (21.0) & 10.8 & (14.8) & $<0.01$ & 20.9 & (23.0) & 18.0 & (18.6) & NS & 35.7 & 414.7 & 0.08 & 0.91 \\
\hline EB & 27.6 & (24.6) & 10.2 & (11.8) & $<0.001$ & 22.6 & (23.1) & 24.0 & (23.7) & NS & 859.8 & 544.6 & 1.57 & 0.20 \\
\hline BCM & 6.0 & (12.5) & 1.8 & $(3.2)$ & $<0.05$ & 6.09 & (15.1) & 4.5 & $(8.3)$ & NS & 63.1 & 125.2 & 0.5 & 0.60 \\
\hline $\mathrm{HM}$ & 19.7 & (22.9) & 6.4 & (15.1) & $<0.001$ & 16.0 & (22.5) & 16.8 & $(21.8)$ & NS & 859.8 & 479.7 & 1.8 & 0.17 \\
\hline M & 12.1 & (21.1) & 6.7 & (11.7) & NS & 11.9 & (23.2) & 10.0 & (17.1) & NS & 471.6 & 377.6 & 1.2 & 0.30 \\
\hline SI & 18.0 & (20.6) & 10.2 & (12.9) & $<0.05$ & 16.3 & (20.5) & 16.1 & (18.8) & NS & 1199.5 & 363.8 & 3.3 & 0.04 \\
\hline A & 7.2 & (15.1) & 2.7 & (8.2) & NS & 6.4 & (15.2) & 5.9 & (13.3) & NS & 44.8 & 196.1 & 0.2 & 0.79 \\
\hline $\mathrm{AB}$ & 30.8 & (31.1) & 9.4 & (12.9) & $<0.001$ & 29.2 & (29.1) & 23.9 & (28.1) & NS & 502.8 & 820.3 & 0.6 & 0.54 \\
\hline $\mathrm{C}$ & 14.2 & (21.4) & 4.3 & (10.6) & $<0.001$ & 16.1 & (22.3) & 9.5 & (18.0) & $<0.05$ & 65.9 & 397.9 & 0.2 & 0.84 \\
\hline W & 9.8 & (17.5) & 10.7 & (22.3) & NS & 9.3 & (17.1) & 10.4 & (19.6) & NS & 339.0 & 349.9 & 0.9 & 0.38 \\
\hline $\mathrm{RP}$ & 29.1 & (25.3) & 18.3 & (19.3) & $<0.05$ & 25.5 & (24.7) & 27.1 & (24.4) & NS & 639.5 & 598.1 & 1.1 & 0.35 \\
\hline $\mathrm{E}$ & 4.5 & (10.8) & 1.5 & $(3.3)$ & NS & 5.2 & $(10.2)$ & 3.1 & $(9.3)$ & NS & 43.1 & 93.9 & 0.4 & 0.6 \\
\hline SDI & 6.9 & (11.5) & 3.1 & (5.8) & NS & 6.9 & (13.8) & 5.5 & (8.3) & NS & 142.7 & 110.4 & 1.3 & 0.27 \\
\hline SDII & 24.8 & (22.8) & 9.3 & (10.8) & $<0.001$ & 23.1 & (23.8) & 20.1 & $(20.3)$ & NS & 521.5 & 464.1 & 1.1 & 0.32 \\
\hline SIP & 10.3 & (15.6) & 9.3 & $(10.5)$ & $<0.001$ & 16.4 & (15.7) & 17.2 & (14.9) & NS & 209.7 & 231.0 & 0.9 & 0.4 \\
\hline
\end{tabular}

\footnotetext{
a Student's $t$ test

b One-way ANOVA

c Values are means (standard deviation)

d Values are mean squares, 2 degrees of freedom

e Values are mean squares, 156 degrees of freedom $N S$, not significant
} 
Table 5 IBQ parameters mean values: comparison according to gender, drug abuse and chronic headache subtype

\begin{tabular}{|c|c|c|c|c|c|c|c|c|c|c|c|c|c|c|}
\hline \multirow[b]{3}{*}{ GH } & \multicolumn{5}{|c|}{ Gender ${ }^{\mathrm{a}}$} & \multicolumn{5}{|c|}{ Drug abuse ${ }^{\mathrm{a}}$} & \multicolumn{4}{|c|}{ Chronic headache subtype ${ }^{b}$} \\
\hline & \multicolumn{2}{|c|}{ Women ${ }^{\mathrm{c}}$} & \multicolumn{2}{|c|}{$\operatorname{Men}^{\mathrm{c}}$} & \multirow{2}{*}{$\begin{array}{c}p \\
<0.05\end{array}$} & \multicolumn{2}{|c|}{ Women $^{\mathrm{c}}$} & \multicolumn{2}{|c|}{$\operatorname{Men}^{\mathrm{c}}$} & \multirow{2}{*}{$\begin{array}{c}p \\
\mathrm{NS}\end{array}$} & \multirow{2}{*}{$\begin{array}{r}\begin{array}{c}\text { Between } \\
\text { groups }^{\mathrm{d}}\end{array} \\
0.04\end{array}$} & \multirow{2}{*}{$\begin{array}{r}\begin{array}{l}\text { Within } \\
\text { groups }\end{array} \\
0.05\end{array}$} & \multirow{2}{*}{$\begin{array}{c}\begin{array}{c}\mathrm{F} \\
\text { ratio }\end{array} \\
0.69\end{array}$} & \multirow{2}{*}{$\begin{array}{c}\begin{array}{c}\mathrm{F} \\
\text { probability }\end{array} \\
0.50\end{array}$} \\
\hline & 0.41 & $(0.23)$ & 0.29 & $(0.22)$ & & 0.38 & $(0.23)$ & 0.38 & $(0.23)$ & & & & & \\
\hline $\mathrm{DC}$ & 0.45 & $(0.27)$ & 0.32 & $(0.25)$ & $<0.05$ & 0.37 & $(0.28)$ & 0.45 & $(0.26)$ & NS & 0.06 & 0.07 & 0.91 & 0.40 \\
\hline SVP & 0.33 & $(0.22)$ & 0.34 & $(0.22)$ & NS & 0.43 & $(0.20)$ & 0.28 & $(0.23)$ & $<0.001$ & 0.08 & 0.05 & 1.64 & 0.19 \\
\hline AI & 0.52 & $(0.34)$ & 0.49 & $(0.36)$ & NS & 0.53 & $(0.35)$ & 0.50 & $(0.34)$ & NS & 0.18 & 0.12 & 1.5 & 0.21 \\
\hline $\mathrm{AD}$ & 0.62 & $(0.31)$ & 0.40 & $(0.31)$ & $<0.001$ & 0.55 & $(0.34)$ & 0.59 & $(0.32)$ & NS & 0.17 & 0.10 & 1.63 & 0.19 \\
\hline $\mathrm{D}$ & 0.53 & $(0.35)$ & 0.64 & $(0.33)$ & NS & 0.58 & $(0.37)$ & 0.54 & $(0.35)$ & NS & 0.23 & 0.12 & 1.89 & 0.15 \\
\hline I & 0.51 & $(0.25)$ & 0.47 & $(0.21)$ & NS & 0.49 & $(0.24)$ & 0.50 & $(0.25)$ & $<0.05$ & 0.19 & 0.06 & 3.22 & $<0.05$ \\
\hline $\mathrm{HI}$ & 0.48 & $(0.17)$ & 0.37 & $(0.20)$ & $<0.01$ & 0.46 & $(0.20)$ & 0.46 & $(0.17)$ & $<0.05$ & 0.003 & 0.03 & 0.10 & 0.90 \\
\hline
\end{tabular}

\footnotetext{
a Student's $t$ test

b One-way ANOVA

${ }^{\mathrm{c}}$ Values are means (standard deviation)

d Values are mean squares, 2 degrees of freedom

e Values are mean squares, 156 degrees of freedom

$N S$, not significant
}

\section{Discussion}

In this study, patients with chronic headache showed a remarkable impairment in most of their daily activities. At the same time they lived their illness poorly. Such alterations appeared to increase with the patient's current age and age at chronic headache onset. The longer was chronic headache duration, the more disability was marked. Female gender was associated with a more severe profile, both in SIP and in IBQ. Analgesic abusers showed some differences in comparison to nonabusers, consisting in a greater difficulty in communication and a more marked tendency to consider themselves to be affected by a psychological disease. Abusers showed higher levels of irritability, indicating feelings of anger and an awareness of interpersonal friction. Moreover, their elevated scores on the hypochondriasis index indicated their current fears and concerns about headache. Chronic migraineurs' profile was more impaired in irritability and social interactions than that of other chronic headache sufferers. This last result may be due to pain severity which is greater in migraine than in tension-type headache.

These results suggest that the complaint of disability and of an abnormal way of living their illness should always be searched for and, where present, discussed as relevant elements both for diagnosis and treatment.
M. Guazzelli

Psychiatric Clinic,

University of Pisa, Pisa, Italy

A.P. Verri • G. Sandrini

IRCCS Mondino,

University of Pavia, Pavia, Italy

M. Nicolodi $•$ S. Canova

Interuniversity Centre of Neurochemistry and Clinical

Pharmacology of Primary Headache,

Florence University, Florence, Italy

F. Moschiano • L. Grazzi • D. D’Amico

C. Besta National Neurological Institute, Milan, Italy

\section{F. Maggioni}

Neurological Clinic,

University of Padua, Padua, Italy

G. Relja

Ospedale Maggiore, Trieste, Italy

A. Alberti • S. Russo

Neurological Clinic,

University of Perugia, Perugia, Italy

\section{References}

1. Pilowsky I (1978) A general classification of abnormal illness behaviour. $\mathrm{Br}$ J Med Psychol 51:131-137
2. Gilson BS, Gilson J, Bergner M, Vesselago M, Kressel S, Bobbitt RA, Pollard WE (1973) Development and application of the Sickness Impact Profile, a pilot study 1972-1973.
Department of Health Services, School of Public Health and Community Medicine, University of Washington, Seattle 